\title{
Quaternary coral reef refugia preserved fish diversity
}

\author{
Loïc Pellissier, ${ }^{1,2}$ Fabien I \\ Michel Kulbicki, ${ }^{4}$ Glenn I \\ David R. Bellwood, ${ }^{11}$ David Mouillot ${ }^{3,11 *}$
}

The most prominent pattern in global marine biogeography is the biodiversity peak in the Indo-Australian Archipelago. Yet the processes that underpin this pattern are still actively debated. By reconstructing global marine paleoenvironments over the past 3 million years on the basis of sediment cores, we assessed the extent to which Quaternary climate fluctuations can explain global variation in current reef fish richness. Comparing global historical coral reef habitat availability with the present-day di_... . oution of 6316 reef fish species, we find that distance from stable coral reef habitats during historical periods of habitat loss explains $62 \%$ of the variation in fish richness, outweighing present-day environmental factors. Our results highlight the importance of habitat persistence during periods of climate change for preserving marine $b^{\text {" }}$ "iversity.

$\mathrm{T}$ ropical marine biodiversity shows a unique longitudinal pattern with a peak of species richness in the Indo-Australian Archipelago (IAA) $(1,2)$. With their biological and structural complexity, coral reefs support

${ }^{1}$ University of Fribourg, Department of Biology, Chemin du Musée 10, CH-1700 Fribourg, Switzerland. ${ }^{2}$ Department of Bioscience, Aarhus University, 8000 C Aarhus, Denmark.

${ }^{3}$ Laboratoire Ecologie des Systèmes Marins Côtiers UMR 5119, CNRS, Institut de Recherche pour le Développement (IRD), Institut Français de Recherche pour l'Exploitation de I Mer, UM2, UM1, cc 093, Place E. Bataillon, FR-34095 Montpellier Cedex 5, France. ${ }^{4}$ IRD, UR 227 CoReUs, LABEX (Laboratoire d'Excellence) Corail, Laboratoire Arago, Boîte Postale 44, FR-66651 Banyuls/mer, France. ${ }^{5}$ CESAB (Centre de Synthèse et d'Analyse sur la Biodiversité)-FRB

(Fondation pour la Recherche sur la Biodiversité), Immeuble Henri Poincaré, Domaine du Petit Arbois, FR-13857 Aix-enProvence cedex 3, France. ${ }^{6}$ Centre for Macroevolution and Macroecology, Research School of Biology, Australian National University, Canberra, ACT 0200, Australia.

${ }^{7}$ Department of Ecology and Evolution, Biophore Building, University of Lausanne, 1015 Lausanne, Switzerland. ${ }^{8}$ Swiss Institute of Bioinformatics, Quartier Sorge, 1015 Lausanne, Switzerland. ${ }^{9}$ Center for Ocean and Ice, Danish Meteorological Institute, Lyngbyvej 100, 2100 Copenhagen, Denmark. ${ }^{10}$ Department of Ecology and Environment. DHI Water and Environment, 2970 Hørsholm, Denmark. ${ }^{11}$ Australian Research Council Centre of Excellence for Coral Reef Studies, and School of Marine and Tropical Biology, James Cook University, Townsville, OLD 4811, Australia.

*Corresponding author. E-mail: david.mouillot@univ-montp2.fr the world's greatest diversity of marine fishes (3-5). Reef-building corals track well-defined conditions of sea surface temperature and light (6) and are thus particularly sensitive to changes in climate and sea level. On short temporal and small spatial scales, coral assemblages exhibit highly dynamic fluctuations in species composition and abundance, with species-specific responses to disturbances $(7,8)$. At longer time scales, fossil records sho $t$ coral reefs may have experienced dramatic contractions in response to environmental shifts. The most striking example is the last interglacial period, $\sim 125,000$ years ago, when a rise in sea surface temperature caused an equatorial retraction of coral reefs with a rapid loss of marine biodiversity (9). Colder temperatures and sea level drops have also been responsible for massive coral habitat loss in the past, with many coral reefs arising after the last glacial maximum (10). Given the dependency of most reef fishes on coral reef habitat $(11,12)$, historical climatic oscillations are likely to have affected fish persistence and thus current biodiversity patterns.

The Quaternary period (2.6 million years ago to present) is characterized by at least 30 glacialinterglacial cycles of repeated global cooling and warming with consequences for reef habitat 
availability. Stable coral reef habitats over geological time may have promoted fish biodiversity by acting as (i) refugia, which preserved species from extinction because of habitat loss $(4,13)$; (ii) sources for the recolonization of unstable areas during more favorable periods $(14,15)$; and (iii) evolutionary cradles with high speciation rates (16). Given these combined benefits, Quaternary coral reef refugia should have left their imprint on current richness patterns of coral reef fishes worldwide. To explore the influence of environmental history on global fish diversity patterns on tropical reefs, we identified the putative locations of refugia, defined as habitat suitable for corals during cold periods, by reconstructing coral reef paleodistributions during the Quaternary. By building on sea surface temperature and sea level paleoconditions inferred from sediment cores $(17,18)$ to bind the coral reef environmental envelope (figs. S1 and S2), we mapped the paleodistribution of this habitat for the past three million years with a temporal resolution of 1000 years (Fig. 1A) by using an accurate model [95\% of correct classification (fig. S3)]. For each current reef, isolation from refugia was computed as the sea distance to historical coral reef habitats across the glaciation cycles (Fig. 1B). We also mapped, at $5^{\circ}$-by- $5^{\circ}$ resolution, the global distribution of fish species richness by using the geographic range of 6316 tropical reef fishes (Fig. 1C). We then predicted fish richness patterns from historical (past coral reef area and isolation from refugia) and contemporary (mean sea surface temperature, coral reef area, and isolation) factors by using a set of bivariate and multivariate linear regression models including quadratic terms to account for nonlinear relationships.

We found that isolation from Quaternary refugia was the primary driver of reef fish richness (Fig. 2A) and that its effect was far greater than all other factors, including past and current coral reef area, isolation, and sea surface temperature (table S1). Areas closer to Quaternary refugia display higher fish richness $\left(R^{2}=0.62 ; P<0.0001\right)$ (Figs. 1 and 2A), emphasizing the crucial role of stable coral reef habitat during the Quaternary. When considering contemporary factors, neither the sea surface temperature $\left(R^{2}=0.25 ; P<\right.$ $0.0001)$ nor the level of isolation of coral reef habitats $\left(R^{2}=0.30 ; P<0.0001\right)$ or even the coral reef area $\left(R^{2}=0.33 ; P<0.0001\right)$ provided near or exceeding explanatory power to isolation from Quaternary refugia (table $\mathrm{S} 1$ ). These observations are supported by two complementary analyses. First, isolation from Quaternary refugia received the highest support over all subset models mixing historical and contemporary factors (table S2). Second, when partitioning the explained variance of fish richness $\left(R^{2}=0.73\right)$ among historical and contemporary factors included in the model, isolation from Quaternary refugia showed the strongest independent effect, with a higher proportion of explained variance $(24.4 \%)$ than current coral reef area, coral reef isolation, and sea surface temperature combined (15.5\%). Furthermore, the explanatory power of historical extent of coral reef habitat on fish richness peaked during time periods when sea temperature was the lowest, causing the strongest coral reef habitat contractions $\left(R^{2}=0.45, P<0.0001\right)$ (figs. S4 and S5). Similar results are obtained when excluding the tropical Eastern Pacific and Atlantic basins that display the highest levels of isolation from refugia and the lowest extents of coral reef habitat during the cold periods compared with those located in the Indo-Pacific, suggesting that our findings are not biased by a basin effect (table S3 and figs. S6 and S7). Taken together, our results highlight how areas that retained suitable coral reef habitat over geological time served as refugia, buffering species from extinction by minimizing stochastic processes leading to population decline $(19,20)$.

The impact of past habitat availability on current fish richness patterns should also depend on recolonization ability, mainly through larval dispersal that varies across families (21). Among the three families investigated (Pomacentridae, damselfishes; Labridae, wrasses; Chaetodontidae, butterflyfishes), damselfishes should show the strongest response to isolation from refugia, given their low swimming ability during the late pelagic stage and shorter pelagic larval duration, compared with wrasses and butterflyfishes (21). We estimated segment breakpoints in the regression models linking fish richness to the isolation from Quaternary refugia to test for a family-specific response (Fig. 2, B to D). Isolation from refugia was closely related to fish richness for the three families, suggesting common drivers (Fig. 2 and table S4), but their breaking points differed (fig. S8). As expected from their ecological characteristics and larval dispersal capacity (21), the damselfishes show a break point in fish richness at a lower level of isolation from refugia $(46.1 \mathrm{~km})$ compared with butterflyfishes $(396.7 \mathrm{~km})$ and wrasses $(291.3 \mathrm{~km})$. Lending additional support to this pattern, the effect of past extent of coral reef habitat is a better predictor of richness for damselfishes than for the two other families (table S4). Indeed, damselfishes richness is especially concentrated in the Indo-Pacific, which maintained extensive refugia during the Quaternary.

Historical barriers, such as those created by sea level drops during the Quaternary, may have played important roles in the isolation of populations by cutting off local sea basins $(22,23)$. Paleohabitat models suggest that not only were

\section{A Past coral reef area}
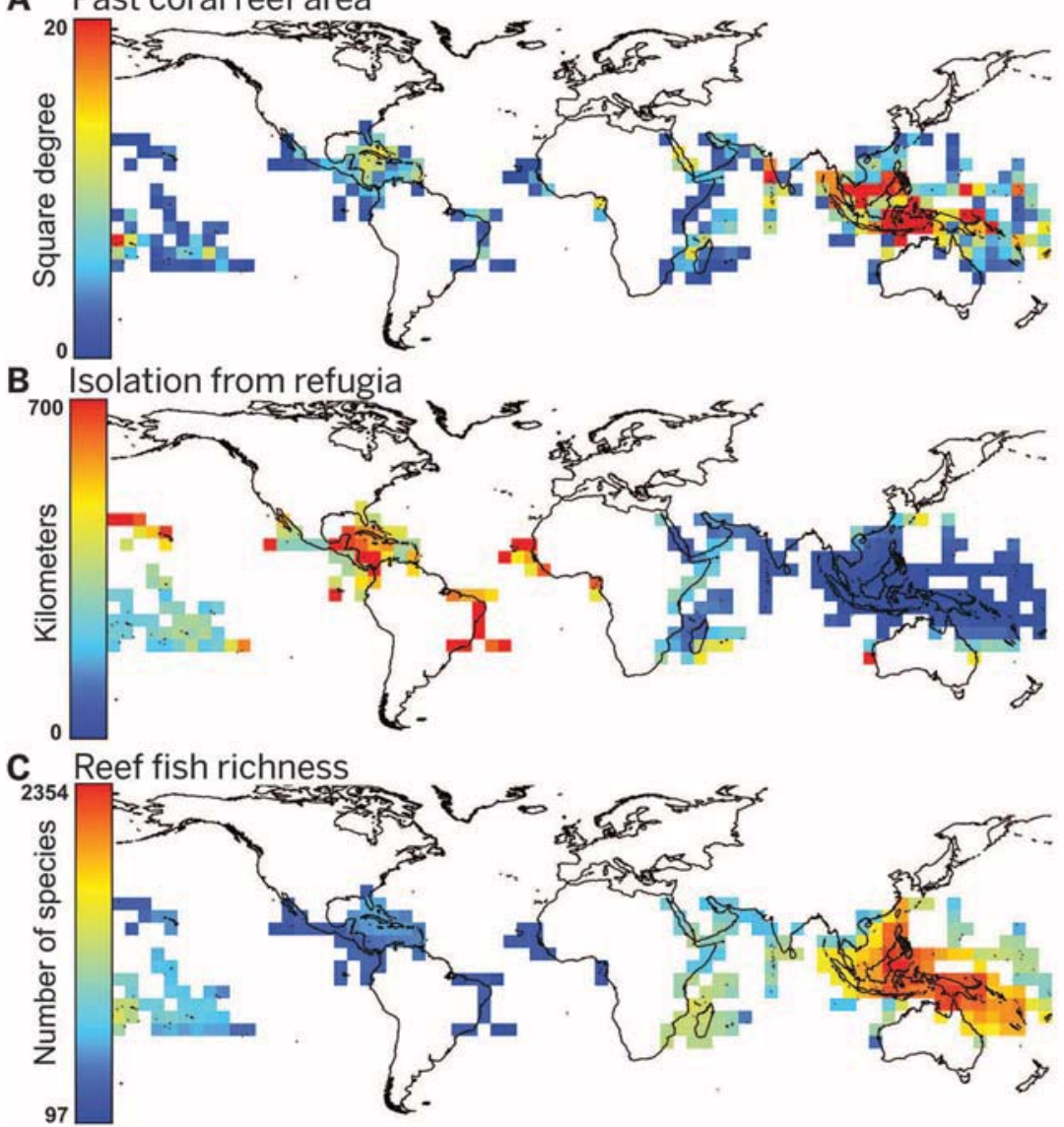

Fig. 1. Location of coral reefs, past isolation, and current fish richness. Maps of (A) the coral reef area per $5^{\circ}$-by- $5^{\circ}$ cell averaged for the periods of marked coral reef contraction, as characterized by lower sea surface temperature and sea level (square degree); (B) standardized isolation from stable coral reef areas across the Quaternary (kilometers); and (C) current global richness of reef fishes (number of species) 
the Atlantic and Indo-Pacific oceans isolated from each other but that coral reefs within the IndoPacific were isolated in refugia such as the Red
Sea, Madagascar, and Maldives, along with multiple small refugia within the IAA (Fig. 3). In particular, we found an increased spatial frag-
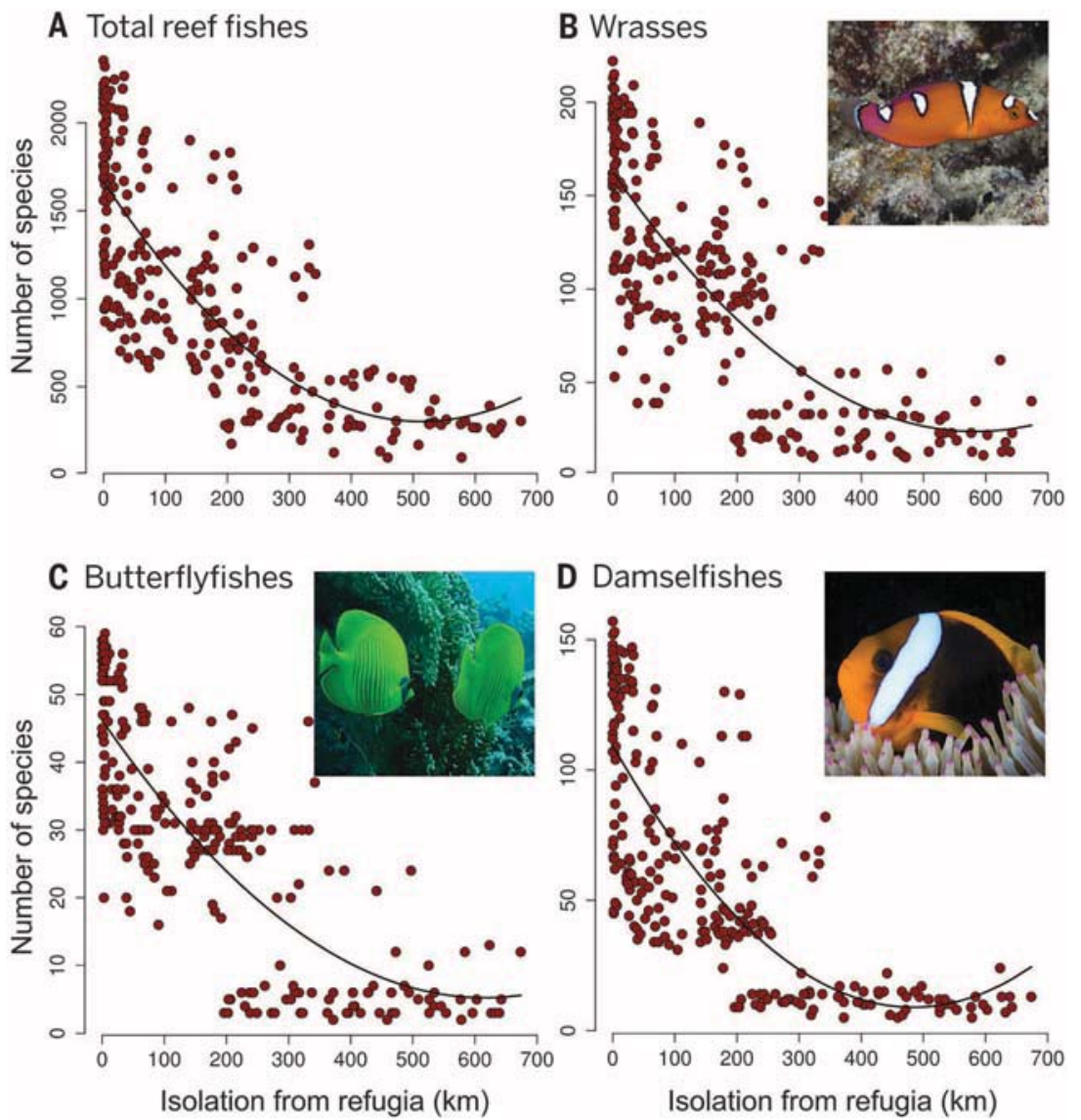

Fig. 2. Relationship between the standardized isolation from stable coral reef areas across the Quaternary and total richness of reef fishes. Shown is the total reef fish richness (A) as well as richness of three families: wrasses (B), butterflyfishes (C), and damselfishes (D). [Photo credits: J. P. Krajewski (B) and (D) and S. Gingins (C)]

Fig. 3. Reef paleodistribution and species age. Projected coral reef habitat for two time periods (yellow) based on historical sea surface temperature and sea level at -21 thousand years (Ky) (A) and -896 Ky (B). Expert-delimited ecoregions based on faunal dissimilarity are shown in shades of blue. The coral reef area for each time step was used to compute the change in habitat fragmentation through time, which is represented as the yellow line in (C). Also shown in black is the histogram of species age for wrasses, butterflyfishes, and damselfishes.


mentation of coral reef habitat over time from the onset of glaciations in the Indo-Pacific ocean (landscape division index, $R^{2}=0.15, P<0.0001$ ) (Fig. 3). Fragmentation was highest during the periods with the coldest temperatures $\left(R^{2}=\right.$ $0.51, P<0.0001$ ) (fig. S9). Our dated phylogenies indicate that a large proportion of fishes within the target families arose in the past 3 million years (percentage of species with an age of divergence from the most closely related sister species $<3$ Ma for wrasses is $19 \%$; damselfishes, 31\%; butterflyfishes, 65\%) (Fig. 3). The number of recently diverged species $(<3 \mathrm{Ma})$ was highest in proximity to refugia where these species could have arisen (wrasses, $R^{2}=0.61$ and $P<0.0001$; butterflyfishes, $R^{2}=0.65$ and $P<$ 0.0001; damselfishes, $R^{2}=0.57$ and $P<0.0001$ ). Our results provide evidence for the role of disconnected but stable habitat area in promoting species diversification during the Quaternary, especially in the Indo-Pacific (24).

High extinction and low speciation rates in areas outside putative refugia can reduce species richness and should also affect the age of lineages represented in species assemblages (25). Refugia are expected to preserve species from extinction and should harbor the oldest species. In contrast, unstable areas are likely to harbor younger colonists, resulting in a narrower range of ages because they lack older species. Consistent with this hypothesis, the difference between the 95th and 5 th percentiles of species age distribution is larger in refugia for all three families (wrasses, $R^{2}=0.22, P<0.0001$; butterflyfishes, $R^{2}=0.32$, $P<0.0001$; and damselfishes, $R^{2}=0.53, P<$ 0.0001 ) (Fig. 4) without any bias related to variation in species richness (fig. S10). The effect of isolation from refugia is weaker for the wrasses than for the other two families (Fig. 4). The oldest wrasses occur both in the Indo-Pacific and in the Atlantic, the latter resulting from Atlantic colonization from the west Tethys Sea 

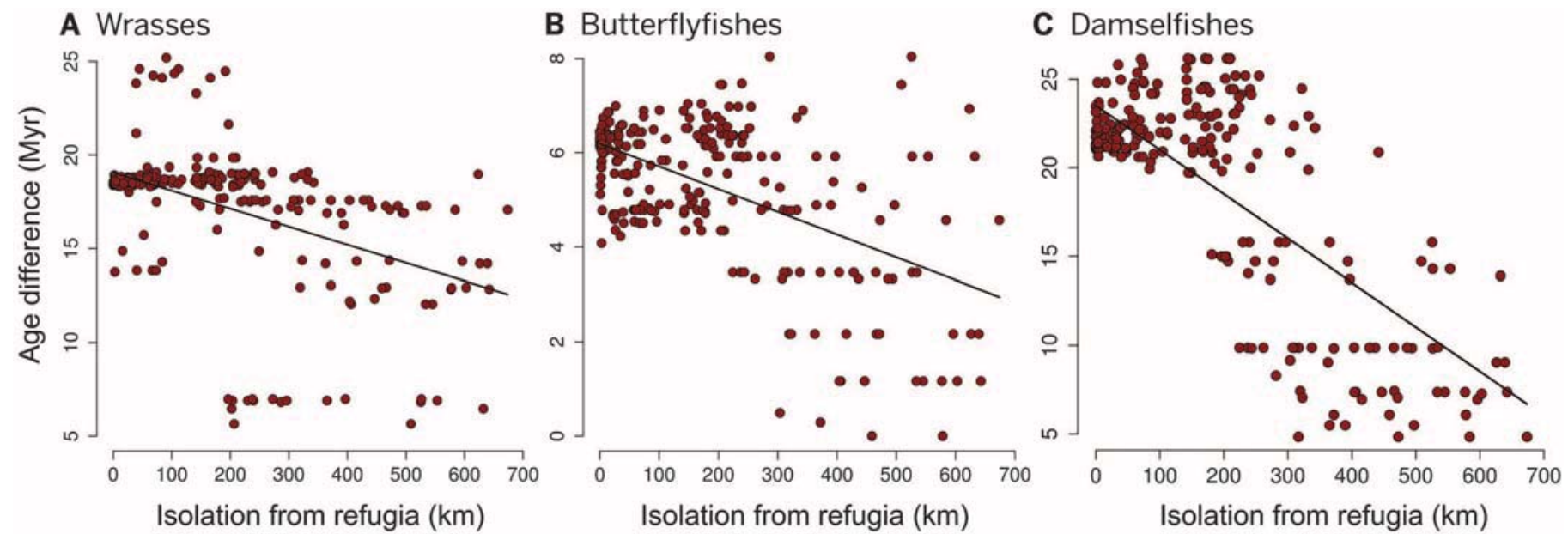

Fig. 4. Isolation distance and species age. (A to C) Relationship between the standardized isolation from stable coral reef areas across the Quaternary (kilometers) and the difference between the 95th and 5th percentile of species age in assemblages in each cell. Cells closer to refugia during the Quaternary have a larger age range because they contain both older and younger species.

$(3,4)$. Because Atlantic lineages are less associated with coral reef habitats $(3,4)$, instability during the Quaternary likely had a lower impact on the persistence of wrasses. In support of this result, the wrasses have exhibited relatively few new species in the past 3 million years (Fig. 3), suggesting a less intense effect of habitat fragmentation during the Quaternary.

Our results highlight the central role of coral reef refugia during Quaternary climatic fluctuations and how isolation from refugia has modulated fish richness patterns. The distance from the Indo-Pacific center was found to be a major determinant of fish richness (26). The Indo-Pacific maintained extensive coral reef refugia during cold periods with low sea level stands (Fig. 1A), in areas including the IAA, Maldives, Madagascar, and Red Sea (Fig. 3). These areas thus appear to have acted as centers of survival, as previously suggested (27, 28). By contrast, in the Atlantic, only very limited areas were suitable for coral reefs during cold periods (Fig. 1A), implying a degradation of Caribbean coral reefs after the onset of glaciation. This may explain the relatively weak association of Caribbean fishes with coral reef habitats (29) and the high extinction rates around 2 to $1 \mathrm{Ma}$ observed in near-shore environments (30). Paralleling results for subtropical rainforest (31), we demonstrate that historical habitat availability in coral reefs is as important as current habitat extent in explaining observed distributions of fish species richness. Our results suggest that the possible "cradle" effect of coral reefs may have arisen from increased fragmentation during episodic cold events, especially in the IAA (Fig. 3). Quaternary climatic fluctuations have left their mark on contemporary patterns of reef fish biodiversity through historical shifts in habitat availability and isolation.

Examining how coral reefs have changed in the past may give new insight into understanding how reef species might respond to global change (32). Our results suggest that current reef fish biodiversity can be primarily explained by past habitat availability. This finding has important implications for conservation of coral reefs worldwide under ongoing climate change. Most notably, the warm refugia that protected species in the past may in turn be the first to be threatened by future warming (33). Ideally, management strategies should focus on the protection of coral reefs over large areas that maintain corridors of suitable habitat that allow the resilience of fish biodiversity through connectivity from historical refugia. Our results emphasize the strong relationship between reef fish biodiversity, past habitat shifts, the role of habitat conservation under climate change, and, more generally, the role of historical habitat shift in shaping the diversity of life we observe today.

\section{REFERENCES AND NOTES}

1. D. R. Bellwood, T. P. Hughes, Science 292, 1532-1535 (2001).

2. W. Renema et al., Science 321, 654-657 (2008).

3. S. A. Price, R. Holzman, T. J. Near, P. C. Wainwright, Ecol. Lett. 14, 462-469 (2011)

4. P. F. Cowman, D. R. Bellwood, J. Biogeogr. 40, 209-224 (2013).

5. V. Parravicini et al., Ecography 36, 1254-1262 (2013).

6. J. A. Kleypas et al., Am. Zool. 39, 146 (1999).

7. J. H. Connell, T. P. Hughes, C. C. Wallace, Ecol. Monogr. 67 461-488 (1997).

8. T. P. Hughes et al., Curr. Biol. 22, 736-741 (2012)

9. W. Kiessling, C. Simpson, B. Beck, H. Mewis,

J. M. Pandolfi, Proc. Natl. Acad. Sci. U.S.A. 109 21378-21383 (2012)

10. J. E. N. Veron, M. Stafford-Smith, Corals of the World (Australian Institute of Marine Science, Townsville, Australia, 2000).

11. M. J. Paddack et al., Curr. Biol. 19, 590-595 (2009).

12. M. C. Bonin, G. R. Almany, G. P. Jones, Ecology 92, 1503-1512 (2011).

13. G. Paulay, Paleobiology 16, 415-434 (1990).

14. A. C. Carnaval, M. J. Hickerson, C. F. Haddad, M. T. Rodrigues, C. Moritz, Science 323, 785-789 (2009).

15. B. Sandel et al., Science 334, 660-664 (2011)

16. D. D. McKenna, B. D. Farrell, Proc. Natl. Acad. Sci. U.S.A. 103, 10947-10951 (2006)

17. K. G. Miller et al., Science 310, 1293-1298 (2005).

18. T. D. Herbert, L. C. Peterson, K. T. Lawrence, Z. Liu, Science 328, 1530-1534 (2010)

19. M. L. Rosenzweig, Species Diversity in Space and Time (Cambridge Univ. Press, Cambridge, 1995).
20. S. L Chown, K. J. Gaston, Trends Ecol. Evol. 15, 311-315 (2000)

21. O. J. Luiz et al., Proc. Natl. Acad. Sci. U.S.A. 110, 16498-16502 (2013)

22. J. W. McManus, "Marine speciation, tectonics, and sea-level changes in Southeast Asia," in Proceedings of the Fifth International Coral Reef Congress, C. Gabrie, B. Salvat, Eds. (International Coral Reef Symposium, Penang, Malaysia, 1985), vol. 4, pp. 133-138.

23. D. C. Potts, in Proceedings of the Fifth International Coral Reef Congress, C. Gabrie, B. Salvat, Eds. (International Coral Reef Symposium, Penang, Malaysia, 1985), vol. 4 pp. 127-132.

24. A. J. Kohn, in Proceedings of the Fifth International Coral Reef Congress, C. Gabrie, B. Salvat, Eds. (International Coral Reef Symposium, Penang, Malaysia, 1995), vol. 4 pp. 139-144.

25. J. Fjeldså, J. C. Lovett, Biodivers. Conserv. 6, 325-346 (1997)

26. C. Mora, P. M. Chittaro, P. F. Sale, J. P. Kritzer, S. A. Ludsin, Nature 421, 933-936 (2003).

27. P. H. Barber, D. R. Bellwood, Mol. Phylogenetics Evol. 35 , 235-253 (2005).

28. D. R. Bellwood, C. P. Meyer, J. Biogeogr. 36, 569-576 (2009).

29. D. R. Bellwood, P. C. Wainwright, in Coral Reef Fishes: Dynamics and Diversity in a Complex Ecosystem, P. F. Sale, Ed. (Academic Press, San Diego, CA, 2002).

30. A. O'Dea et al., Proc. Natl. Acad. Sci. U.S.A. 104, 5501-5506 (2007)

31. C. H. Graham, C. Moritz, S. E. Williams, Proc. Natl. Acad. Sci. U.S.A. 103, 632-636 (2006).

32. J. M. Pandolfi, S. R. Connolly, D. J. Marshall, A. L. Cohen, Science 333, 418-422 (2011).

33. C. Mora et al., PLOS Biol. 11, e1001682 (2013).

\section{ACKNOWLEDGMENTS}

This study was supported by grants from the Danish Council for Independent Research no. 12-126430 to L.P.. Marie Curie IOF-GA-2009-236316 to D.M., FRB CESAB-General Approach to Species-Abundance Relationships in a context of global change, reef fish species as a model, and the Australian Research Council. We thank three anonymous reviewers for valuable comments on the manuscript. We thank J. P. Krajewski and S. Gingins for the fish images. Data are available in the supplementary materials.

\section{SUPPLEMENTARY MATERIALS}

Materials and Methods

Figs. S1 to S14

Tables S1 to S4

References (34-80)

Database S1 